\title{
Analysis on the Factors Influencing the Behavior of Purchasing Enterprise Brand Fruits: Empirical Study Based on 312 Consumers in China
}

\author{
Wenbin Jiang (D), Liyu Ju $(\mathbb{D}$, Yongju Zhang $(\mathbb{D}$, and Ziyu Li $\mathbb{D}$ \\ Economics College, Qingdao Agricultural University, 700 Great Wall Road, Chengyang District, Qingdao, Shandong, China \\ Correspondence should be addressed to Liyu Ju; 201301018@qau.edu.cn
}

Received 7 April 2021; Revised 18 November 2021; Accepted 24 November 2021; Published 6 December 2021

Academic Editor: Antonio Piga

Copyright ( 2021 Wenbin Jiang et al. This is an open access article distributed under the Creative Commons Attribution License, which permits unrestricted use, distribution, and reproduction in any medium, provided the original work is properly cited.

\begin{abstract}
Based on summarizing the factors that influence consumers' purchasing of fruits and vegetables, by establishing the theoretical framework that describes the factors influencing the behavior of purchasing enterprise brand fruits, designing the questionnaire, collecting data, and analyzing the data of 312 consumers by binary logistic regression, this article finds that there are mainly 6 factors influencing the behavior of purchasing enterprise brand fruits, namely, gender, the convenience of purchase, taste, evaluation after tasting, tasted or not, and whether relatives or friends buy. Among them, the first four factors have a positive effect, while the last two have a negative effect. The biggest influential factor is whether relatives or friends buy, followed by tasted or not, the third is an evaluation after tasting, and the fourth is the convenience of purchase. Taste and gender are, respectively, ranked fifth and sixth. Based on the above conclusions, this article puts forward some countermeasures and suggestions, which can be listed as follows: to expand the marketing channels of enterprise brand fruits, to improve the convenience of purchase, to improve the quality of enterprise brand fruits, to pay attention to the improvement of taste, to give full play to the publicity role of the government and enterprises, and to improve the popularity of enterprise brand fruits.
\end{abstract}

\section{Introduction}

With the development of China's economy and the continuous improvement of people's living standards, people consume more fruits than before and demand higher quality fruits. They pay more attention to green, healthy, delicious, and nutritious fruits. However, the quality of fruits has implicit characteristics. It is difficult for consumers to identify the quality, nutrition, and pesticide residues through the appearance. Creating a fruit brand is a feasible way to solve this problem. In the minds of consumers, brands represent trust, safety, and high quality. The unique attributes or identity of brands can distinguish high-quality fruits from inferior fruits. However, presently, the fruit brands known to consumers are mainly regional public brands, in the form of "regional name + category name," such as Laiyang pear and Yantai apple. Regional public brands of fruits can weaken the concealment of regional fruits in quality, resulting in uneven quality and the existence of the "Gresham's law" phenomenon. The biggest difference between regional public brands and enterprise brands is that enterprise brands can distinguish their fruits from similar fruits and can also give the brand image of "higher price for better quality." Therefore, this article takes enterprise brand fruits as the breakthrough point and explores the factors influencing consumers' purchase behavior, to fundamentally solve the regional challenge of "high-quality fruits cannot get high price," clarify the main factors influencing consumers' purchasing enterprise brand fruits, improve consumers perception of quality, and reasonably guide consumers to purchase high-quality fruits at the right price.

In the existing studies, experts and scholars have studied consumers behavior in purchasing fruits and vegetables from different perspectives. First of all, in terms of influencing factors, personal factors, social factors, and cognitive factors are the main factors influencing consumers purchase 
behavior. Personal factors mainly include income, gender, age, marital status, occupation, family size, education level, etc. $[1,2]$. Social factors mainly include social class, urbanrural differences, urbanization level, etc. [2-4]. Cognitive factors mainly include quality, variety, origin, safety, price, channel, and brand [5-8]. Secondly, in terms of purchasing channels, consumers have different types of behavioral preferences when purchasing fruits and vegetables in farmers' markets, supermarkets, community outlets, street vendors, online stores, etc., and they consider take different factors when choosing different channels $[9,10]$. However, the price of products has a significant impact on offline consumers' choosing channels [11]. For online consumers, the nature of the purchase, purchasing habits, products characteristics, and ease of mailing are the main considerations $[12,13]$. Online consumers will also pay attention to the initial comments and additional comments from other consumers [14]. Moreover, the COVID-19 pandemic has significantly changed consumers' food purchasing and eating habits. Consumers are more likely to purchase food online that can reduce the spread of COVID-19 $[15,16]$. This new shopping trend led to the evolution of modern value chains for fresh agricultural produce [17]. Furthermore, in terms of the safety of fruits and vegetables, consumers have a low awareness of the quality and safety, such as pesticide residues $[18,19]$. The acceptance degree of premium for safe fruits and vegetables is related to consumers' income. Consumers with higher income are more willing to purchase safe fruits and vegetables [19]. Effective and continuous food safety education is important to improve consumers' knowledge of food safety [20]. However, with the continuous improvement of consumers' awareness, the proportion of purchasing fruits and vegetables with certification and traceability is increasing [21, 22]. Finally, in terms of research on brands of fruits and vegetables, most consumers believe that it is necessary to build fruit brands, but their cognition of fruit brands just stays on the surface. The cognitive level decreases with the growth of consumers but increases with the improvement of educational level [23-25], and consumers are less willing to pay a premium for brands [25]. The authenticity and promotion of brands will increase consumers' satisfaction and loyalty, and they will also significantly increase consumers' purchasing frequency [26].

From the present studies, it can be seen that there are abundant researches on consumers' willingness, behavior, channel choice, and quality of fruits and vegetables [2-8]. Recent researches on fruits and vegetables consumption behavior have mostly focused on online shopping, traceability, etc. $[12,13]$. Some experts and scholars have also studied the brands of fruits and vegetables [22-26]. All of these have laid a good foundation for this article. Domestic and foreign scholars have conducted in-depth studies on consumers' purchasing behavior from the perspectives of psychology, behavioristics, and economics, including consumers' factors, product factors, situational factors, social and cultural factors, business factors, etc. However, there are relatively few studies on systematically and comprehensively exploring the factors influencing the behavior of purchasing enterprise brand fruits. Based on the above analysis, the objective of the present survey is to analyze the factors and degree of influencing the behavior of purchasing enterprise brand fruits from the perspective of consumers' characteristics, their own experience, the surrounding environment, and product characteristics, which will help enrich the existing researches that would help educators, farmers, and others to best understand the most important issues for consumers. The purpose of this article is also to put forward countermeasures and suggestions for promoting the virtuous development of enterprise brand fruits.

\section{Materials and Methods}

2.1. Theoretical Framework. Consumers' purchasing behavior is an extremely complex process, which is the result of many factors. According to the consumer behavior theory, the factors influencing consumers' decisions mainly come from two aspects: one is the characteristics of consumers themselves, such as gender, age, education, income, and family size $[1,2]$; the other is the external environment, such as social culture, social class, related groups, and family background [2-4]. Based on the consumer behavior theory and previous researches, this article will analyze the factors influencing consumers' behavior of purchasing enterprise brand fruits from the following two aspects. One is the internal factors of consumers. Different from individual consumption, purchasing brand fruits is a kind of household consumption. Therefore, the analysis on the internal factors should not only include consumers' characteristics and cognitive factors but also include the characteristics of the whole family. As for personal characteristics, the variables introduced in this article mainly include gender, age, occupation, educational background, and so on. The cognitive factor mainly refers to consumers' recognition degree of enterprise brand fruits. Family characteristics include monthly household income, marital status, and so on. The other is the external environmental factors which mainly refer to the attributes of brand fruits, taste experience, the influence of others, and marketing factors. These factors include freshness preservation, the convenience of purchase, price, taste, nutrition, quality certification, publicity by governments and enterprises, the influence from relatives or friends, the experience about enterprise brand fruits before purchase, and so on. Based on the above analysis, the theoretical framework is established as shown in Figure 1.

2.2. Model Construction. To study consumers behavior of purchasing enterprise brand fruits, the behavior can be divided into two cases: "purchased" and "not purchased," and it is used as the dependent variable. Therefore, the dependent variable in this article is binary, and it is suitable for the binary logistic model.

The logistic function is also called the growth function. The common expression of binary logistic probability function is as follows:

$$
P\left(Y=1 \mid x_{1}, x_{2}, \ldots, x_{n}\right) \frac{1}{1+e^{-\left(\beta_{0}+\beta_{1} x_{1}+\ldots .+\beta_{n} x_{n}\right)}} .
$$




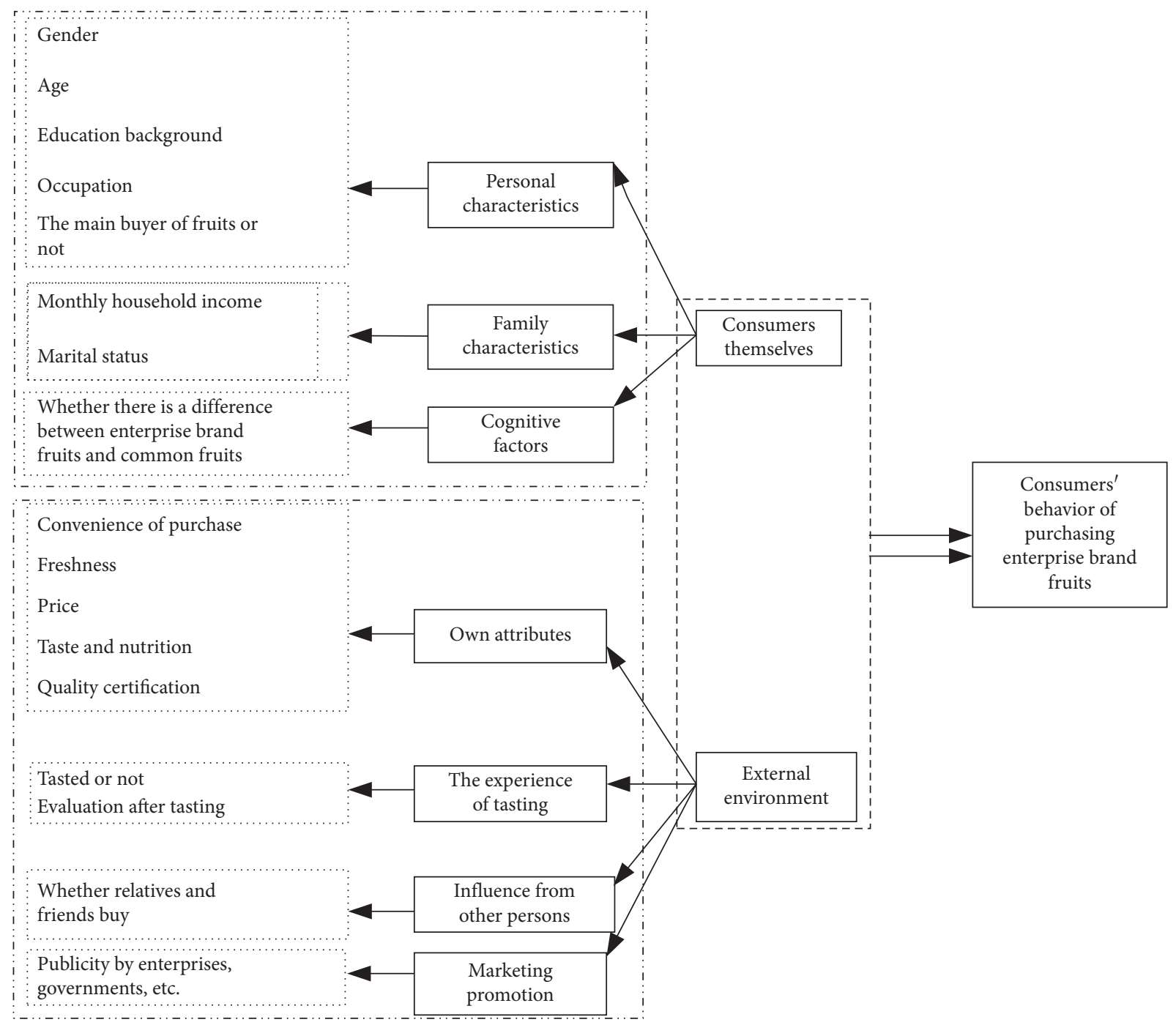

FIGURE 1: Theoretical framework of the factors influencing the behavior of purchasing enterprise brand fruits.

To express the equation as a linear form of the independent variables, a series of transformations are carried out:

$$
\frac{p}{(1-p)}=e^{\left(\beta_{0}+\beta_{1} x_{1}+\ldots+\beta_{n} x_{n}\right)}
$$

can begotten. Take the logarithm of both sides of the equation, and after definition and naming, a linear expression between the probability function and the independent variables is obtained; it is

$$
\operatorname{logitp}=\ln \frac{p}{(1-p)}=\beta_{0}+\beta_{1} x_{1}+\ldots+\beta_{n} x_{n} .
$$

In the equation, $x_{i}$ represents the $i$ factor which can influence consumers' behavior of purchasing enterprise brand fruits, $\beta_{i}$ is its regression coefficient, $n$ represents the number of the independent variables and also the number of influencing factors, and $P$ represents the probability of consumers purchasing enterprise brand fruits under the action of influencing factors $(n)$.
2.3. Data Source. Based on the above theoretical framework, the questionnaire is designed, which is divided into three parts: the cognition and attitude of enterprise brand fruits, basic personal and family information, and purchasing behavior and characteristics of enterprise brand fruits. The definition of indicators in the questionnaire is shown in Table 1. The questionnaire is revised based on the presurvey, and the final questionnaire is distributed through the Questionnaire Star platform during March 2-15, 2021. 312 questionnaires are collected; the effective rate is $100 \%$.

\section{Results and Discussion}

\subsection{Descriptive Statistics of Sample Characteristics}

3.1.1. Gender. As can be seen from Table 2, among the respondents, $61.54 \%$ are female and $38.46 \%$ are male. The proportion of females is higher than that of males. 
TABLE 1: The table of indicators' definition.

\begin{tabular}{|c|c|}
\hline Indicator & Definition \\
\hline \multicolumn{2}{|l|}{ The dependent variable } \\
\hline Purchased or not & $1=$ yes, $0=$ no \\
\hline \multicolumn{2}{|l|}{ The independent variables } \\
\hline Gender & $1=$ male, $2=$ female \\
\hline Age & Numerical value \\
\hline Education background & $\begin{array}{c}1=\text { primary school and below, } 2=\text { junior high school, } 3=\text { high school or technical } \\
\text { secondary school, } 4=\text { university or junior college, } 5=\text { graduate student }\end{array}$ \\
\hline & $\begin{array}{l}1=\text { person in charge of the party, government, and enterprises, } 2=\text { general staff of } \\
\text { party, government, and enterprises. } 3=\text { business personnel, } 4=\text { service personnel, }\end{array}$ \\
\hline Occupation & $5=$ professional and technical personnel, $6=$ self-employed workers, \\
\hline & $\begin{array}{c}7=\text { production, transportation workers and related personnel, } 8=\text { unemployed } \\
\text { personnel, } 9=\text { other occupations }\end{array}$ \\
\hline The main buyer of fruits or not & $1=$ yes, $2=$ no \\
\hline Monthly household income & Numerical value \\
\hline Marital status & $1=$ yes, $2=$ no \\
\hline $\begin{array}{l}\text { Whether there is a difference between enterprise } \\
\text { brand fruits and common fruits }\end{array}$ & $\begin{array}{c}1=\text { No difference, } 2=\text { little difference, } 3=\text { unclear, } 4=\text { significant difference, } \\
5=\text { great difference }\end{array}$ \\
\hline Convenience of purchase & $\begin{array}{c}1=\text { very inconvenient, } 2=a \text { little inconvenient, } 3=\text { average, } 4=\text { relatively } \\
\text { convenient, } 5=\text { very convenient }\end{array}$ \\
\hline Freshness & $\begin{array}{c}1=\text { no effect at all, } 2=\text { almost no effect, } 3=\text { average, } 4=\text { large effect, } 5=\text { very large } \\
\text { effect }\end{array}$ \\
\hline Price & $\begin{array}{c}1=\text { no effect at all, } 2=\text { almost no effect, } 3=\text { average, } 4=\text { large effect, } 5=\text { very large } \\
\text { effect }\end{array}$ \\
\hline Taste & $\begin{array}{c}1=\text { no effect at all, } 2=\text { almost no effect, } 3=\text { average, } 4=\text { large effect, } 5=\text { very large } \\
\text { effect }\end{array}$ \\
\hline Nutrition & $\begin{array}{c}1=\text { no effect at all, } 2=\text { almost no effect, } 3=\text { average, } 4=\text { large effect, } 5=\text { very large } \\
\text { effect }\end{array}$ \\
\hline Quality certification & $\begin{array}{c}1=\text { no effect at all, } 2=\text { almost no effect, } 3=\text { average, } 4=\text { large effect, } 5=\text { very large } \\
\text { effect }\end{array}$ \\
\hline Tasted or not & $1=$ yes, $2=$ no \\
\hline Evaluation after tasting & $1=$ very bad, $2=$ not so good, $3=$ average, $4=$ fairly good, $5=$ very good \\
\hline Whether relatives or friends buy & $1=$ yes, $2=$ no \\
\hline Publicity by enterprises and governments & $1=$ very small, $2=$ relatively small, $3=$ average, $4=$ relatively large, $5=$ very large \\
\hline
\end{tabular}

TABLe 2: Distribution of the respondents' gender.

\begin{tabular}{lcc}
\hline & Amount & Proportion (\%) \\
\hline Male & 120 & 38.46 \\
Female & 192 & 61.54 \\
Total & 312 & \\
\hline
\end{tabular}

3.1.2. Education Background. As can be seen from Table 3, the respondents with college or junior college education account for the highest proportion, followed by graduate students, and then those with high school or technical secondary school education. Only $1.28 \%$ of the respondents have junior high school education or below, indicating that the respondents generally have a relatively high educational level.

3.1.3. Marital Status. As can be seen from Table 4, among the respondents, $56.73 \%$ are married and $43.27 \%$ are unmarried. The proportion of married respondents is higher than that of the unmarried ones.

3.1.4. Occupation Status. As can be seen from Table 5, among the respondents, other occupations account for the highest proportion, followed by professional and technical personnel. The third is the general staff of the party, government, and enterprises. The fourth is service personnel. Business personnel ranked the fifth. The proportions of selfemployed workers, unemployed personnel, the person in charge of the party, government and enterprises, production and transportation workers, and related personnel are relatively low.

\subsection{The Results of Basic Regression}

3.2.1. Testing of Validity and Reliability. In the process of sorting out the acquired data, the outliers are eliminated firstly, and the missing values are replaced by the mean method. To test the reliability of the questionnaire, SPSS20.0 software is used to analyze the reliability of the questionnaire, and Cronbach's a coefficient is used to calculate the reliability of the analysis. The closer Cronbach's coefficient is to 1 , the better the reliability of the questionnaire is. If 
TABLE 3: Distribution of the respondents' educational background.

\begin{tabular}{lcc}
\hline Level of education & Amount & Proportion (\%) \\
\hline Primary school and below & 1 & 0.32 \\
Junior high school & 3 & 0.96 \\
High school or technical secondary school & 13 & 4.17 \\
University or junior college & 188 & 60.26 \\
Graduate student & 107 & 34.29 \\
Total & 312 & 100 \\
\hline
\end{tabular}

TABLE 4: Distribution of the respondents' marital status.

\begin{tabular}{lcc}
\hline & Amount & Proportion (\%) \\
\hline Yes & 177 & 56.73 \\
No & 135 & 43.27 \\
Total & 312 & \\
\hline
\end{tabular}

TABle 5: Distribution of the respondents' occupation.

\begin{tabular}{lcc}
\hline & Amount & Proportion (\%) \\
\hline Person in charge of the party, government, and enterprises & 9 & 2.88 \\
The general staff of the party, government, and enterprises & 62 & 19.87 \\
Business personnel & 28 & 8.97 \\
Service personnel & 33 & 10.58 \\
Professional, technical workers, and related personnel & 64 & 20.51 \\
Self-employed workers & 16 & 5.13 \\
Production and transportation workers and related personnel & 1 & 0.32 \\
Unemployed persons & 14 & 4.49 \\
Other occupations & 85 & 27.24 \\
Total & 312 & \\
\hline
\end{tabular}

Cronbach's coefficient is greater than 0.7 , the reliability of the questionnaire is high. As can be seen from Table 6, Cronbach's coefficient of the scale is 0.733 , which can pass the reliability test.

The validity of the questionnaire is divided into content validity and structure validity. As concerns content validity, the questionnaire is designed based on existing studies, which are fully used for reference of the existing researches to ensure content validity. In terms of structure validity, the method of exploratory factor analysis is used to analyze the value of KMO and the results of Bartlett's test of sphericity. To ensure structural validity, the value of KMO should be greater than 0.5 . As can be seen from Table 6, the value of $\mathrm{KMO}$ is 0.739 , and Bartlett's test of sphericity has been passed $(P<0.05)$. The structural validity of the questionnaire is good. In general, the questionnaire has passed the validity test.

3.2.2. Test of Common Method Deviation. To test common method deviation, Harman's single factor test method is adopted. If there is more than one factor with an eigenvalue greater than 1 and the variance explanation of the first factor is not more than $40 \%$, the common method deviation can pass the test $[27,28]$. As shown in Table 7 , a total of three common factors are extracted, and their eigenvalues are all greater than 1. In addition, the variance explanation of the first factor is $33.57 \%$, so the common method deviation passes the test.
3.2.3. Correlation Analysis between the Factors Influencing the Behavior of Purchasing Enterprise Brand Fruits and the Dependent Variable. To clarify the correlation degree between each influencing factor and the dependent variable, and to lay a foundation for the subsequent analysis, the correlation analysis is carried out. First, the data of age and monthly family income are logarithmically processed. And then a partial correlation test is performed. As can be seen from Table 8 , only gender $\left(0.039^{* *}\right)$, the convenience of purchase $\left(0.071^{*}\right)$, taste $\left(0.043^{* *}\right)$ tasted or not $\left(0.010^{* * *}\right)$, evaluation after tasting $\left(0.024^{* *}\right)$, and whether relatives or friends buy $\left(0.000^{* * *}\right)$ have passed the significance test and have a correlation with the dependent variable, which could be analyzed by the binary logistic model.

3.2.4. Multiple Collinearity Test of the Factors Influencing the Behavior of Purchasing Enterprise Brand Fruits. Based on the above analysis, before the above six factors are included in the model, the multiple collinearity test among the factors is necessary. As can be seen from Table 9, the VIF values of the above six independent variables are all less than 5 . The multiple collinearity test is passed and binary logistic analysis can be performed.

3.2.5. Binary Logistic Analysis of the Factors Influencing the Behavior of Purchasing Enterprise Brand Fruits. After binary logistic analysis, the test of the model is very significant 
TABLE 6: Reliability and validity tests of the questionnaire.

Cronbach's a

$\mathrm{KMO}$

Bartlett's test of sphericity

\subsection{3}

0.739

Approximate chi-square

$\mathrm{d} f$

Sig.
600.146

36

0.000

TABLE 7: Explanation of the total variance.

\begin{tabular}{|c|c|c|c|c|c|c|}
\hline \multirow{2}{*}{ Ingredients } & \multicolumn{3}{|c|}{ Initial eigenvalue } & \multicolumn{3}{|c|}{ Extracting the sum of squares and loading } \\
\hline & Summation & $\%$ of the variance & Cumulative \% & Summation & $\%$ of the variance & Cumulative \% \\
\hline 1 & 3.021 & 33.570 & 33.570 & 3.021 & 33.570 & 33.570 \\
\hline 2 & 1.233 & 13.698 & 47.268 & 1.233 & 13.698 & 47.268 \\
\hline 3 & 1.148 & 12.760 & 60.028 & 1.148 & 12.760 & 60.028 \\
\hline 4 & .930 & 10.338 & 70.367 & & & \\
\hline 5 & .720 & 7.997 & 78.364 & & & \\
\hline 6 & .671 & 7.460 & 85.823 & & & \\
\hline 7 & .476 & 5.283 & 91.107 & & & \\
\hline 8 & .472 & 5.246 & 96.352 & & & \\
\hline 9 & .328 & 3.648 & 100.000 & & & \\
\hline
\end{tabular}

TABLE 8: Correlation test between the factors influencing the behavior of purchasing enterprise brand fruits and the dependent variable.

\begin{tabular}{lcc}
\hline & Correlation & Significance (bilateral) \\
\hline Gender & 0.121 & $0.039^{* *}$ \\
Age & 0.032 & 0.587 \\
Education background & -0.009 & 0.878 \\
Occupation & -0.078 & 0.185 \\
The main buyer of fruits or not & -0.014 & 0.813 \\
Monthly household income & 0.044 & 0.453 \\
Marital status & 0.036 & 0.543 \\
Whether there is a difference between enterprise brand fruits and common fruits & -0.018 & 0.764 \\
Convenience of purchase & 0.106 & $0.071^{*}$ \\
Freshness & 0.013 & 0.830 \\
Price & -0.050 & 0.391 \\
Taste & 0.118 & $0.043^{* *}$ \\
Nutrition & -0.020 & 0.739 \\
Quality certification & -0.040 & 0.498 \\
Tasted or not & -0.150 & $0.010^{* * *}$ \\
Evaluation after tasting & 0.132 & $0.024^{* *}$ \\
Whether relatives or friends buy & -0.393 & $0.000^{* * *}$ \\
Publicity by enterprises and governments & 0.030 & 0.607 \\
\hline
\end{tabular}

Note: ${ }^{*}$ means significant at $10 \%$ level, ${ }^{* *}$ means significant at $5 \%$ level, and ${ }^{* * *}$ means significant at $1 \%$ level.

TABLE 9: Multiple collinearity test of the factors influencing the behavior of purchasing enterprise brand fruits.

\begin{tabular}{|c|c|c|c|c|c|c|c|}
\hline & \multicolumn{2}{|c|}{$\begin{array}{c}\text { Nonstandardized } \\
\text { coefficient }\end{array}$} & \multirow{2}{*}{$\begin{array}{c}\text { Standardized coefficient } \\
\text { Trial version }\end{array}$} & \multirow[t]{2}{*}{$\mathrm{t}$} & \multirow[t]{2}{*}{ Sig. } & \multicolumn{2}{|c|}{$\begin{array}{l}\text { Collinearity } \\
\text { statistics }\end{array}$} \\
\hline & $B$ & Standard error & & & & Tolerance & VIF \\
\hline (Constant) & 0.623 & 0.171 & & 3.641 & 0 & & \\
\hline Gender & 0.088 & 0.041 & 0.104 & 2.168 & 0.031 & 0.962 & 1.04 \\
\hline Convenience of purchase & 0.057 & 0.024 & 0.12 & 2.348 & 0.019 & 0.84 & 1.191 \\
\hline Taste & 0.055 & 0.023 & 0.119 & 2.409 & 0.017 & 0.895 & 1.117 \\
\hline Tasted or not & -0.115 & 0.04 & -0.139 & -2.895 & 0.004 & 0.956 & 1.045 \\
\hline Evaluation after tasting & 0.074 & 0.033 & 0.117 & 2.239 & 0.026 & 0.809 & 1.236 \\
\hline Whether relatives or friends buy & -0.378 & 0.049 & -0.38 & -7.661 & 0 & 0.89 & 1.124 \\
\hline
\end{tabular}

$($ Sig. $=0.000)$. As can be seen from Table 8, the six variables selected by the correlation test have passed the significance test. After calculation, the standardized regression coefficients of the six factors are shown in Table 10. As to purchasing enterprise brand fruits or not, the factor "whether relatives or friends buy" plays the biggest role 
TABLE 10: Binary logistic analysis of the factors influencing the behavior of purchasing enterprise brand fruits.

\begin{tabular}{|c|c|c|c|c|c|c|c|}
\hline & $\mathrm{B}$ & Standardized coefficient & S.E, & Wals & $d f$ & Sig. & $\operatorname{Exp}(B)$ \\
\hline Gender & 0.697 & 0.187 & 0.346 & 4.059 & 1.000 & $0.044^{* *}$ & 2.007 \\
\hline Convenience of purchase & 0.456 & 0.220 & 0.208 & 4.813 & 1.000 & $0.028^{* *}$ & 1.578 \\
\hline Taste & 0.439 & 0.218 & 0.188 & 5.443 & 1.000 & $0.020^{* *}$ & 1.551 \\
\hline Tasted or not & -0.968 & -0.267 & 0.351 & 7.616 & 1.000 & $0.006^{* * *}$ & 0.380 \\
\hline Evaluation after tasting & 0.611 & 0.221 & 0.269 & 5.169 & 1.000 & $0.023^{* *}$ & 1.842 \\
\hline Whether relatives or friends buy & -2.080 & -0.477 & 0.353 & 34.818 & 1.000 & $0.000^{* * *}$ & 0.125 \\
\hline Constant & -0.592 & & 1.333 & 0.198 & 1.000 & 0.657 & 0.553 \\
\hline
\end{tabular}

Note: ${ }^{*}$ means significant at $10 \%$ level, ${ }^{* *}$ means significant at $5 \%$ level, and ${ }^{* * *}$ means significant at $1 \%$ level.

(0.477), the second is tasted or not (0.267), the third is an evaluation after tasting $(0.221)$, the fourth is the convenience of purchase (0.220), the fifth is taste (0.218), and the sixth is gender (0.187).

Among the above influencing factors, gender, the convenience of purchase, a taste of enterprise brand fruits, and evaluation after tasting have a positive effect on purchased or not, while tasted or not and whether relatives or friends buy have a negative effect. They will be analyzed, respectively, as follows.

3.2.6. Discussion. According to the research hypothesis, the factors influencing consumers' purchasing enterprise brand fruits and vegetables mainly include consumers' factors and external environmental factors. The study results are consistent with the theoretical framework.

Firstly, gender, the convenience of purchase, taste, and evaluation after tasting. In terms of gender, compared with male, female is more inclined to purchase enterprise brand fruits. Among the survey respondents, female accounts for $61.54 \%$. It is clear that female prefers enterprise brand fruits. As to convenience of purchase, according to the statistical results, the proportion of the respondents who think it is relatively convenient to purchase enterprise brand fruits is the highest (41.67\%). And the more convenient the purchase is, the bigger possibility it is to be purchased. In terms of taste, compared with common fruits, the respondents who think taste has an important influence take the highest proportion (42.95\%), and with the increase of influence, consumers are more likely to purchase enterprise brand fruits. At last, in terms of evaluation after tasting, $56.73 \%$ of the respondents think that it is good after tasting, ranking the first. Their evaluation is positively proportional to the possibility of purchasing enterprise brand fruits.

Secondly, as concerns tasted or not and whether relatives or friends buy, $53.53 \%$ of the respondents have tasted enterprise brand fruits before purchasing for the first time, and consumers who have not tasted are more inclined not to purchase. In terms of whether relatives and friends buy, in all samples, $77.88 \%$ of the respondents have relatives and friends who have bought enterprise brand fruits. From the results of empirical analysis, it can be seen that consumers whose relatives and friends have not bought enterprise brand fruits are more inclined not to purchase them.

Judging from the results of this study, the influence of consumers' factors (including gender, age, marital status, education, occupation, income, etc.) [1-8] and external environmental factors (including price, quality, safety, convenience, origin, etc.) $[6,8,10,15-20]$ on the behavior of purchasing brand fruits and vegetables is consistent with the existing researches. Different from the existing researches, this study demonstrates the influence of posttasting purchase and posttasting evaluation. Moreover, the purchase experience and experience sharing from relatives and friends also have a direct influence on consumers' purchase behavior, which is rarely mentioned in the existing researches. The factors that influence consumers' purchase behavior will change in different situations. For example, COVID-19 has caused consumers to put forward higher requirements for the channels and safety of purchasing fruits and vegetables [15-17]. This study will dynamically adjust and explore the factors influencing consumers' purchase behavior, which is one of the research directions in the future.

\section{Conclusions and Countermeasures}

4.1. Conclusions. Through the above analysis, it can be seen that the factors influencing the behavior of purchasing enterprise brand fruits are mainly divided into two aspects, namely, consumers themselves and the external environment. Six significant factors are included. They are gender, the convenience of purchase, taste, evaluation after tasting, tasted or not, and whether relatives or friends buy. Except for gender which belongs to consumers themselves aspect, all other factors belong to the external environment aspect. Among them, female is more likely to purchase enterprise brand fruits. The greater the convenience of purchase, the more the attention to the taste of fruits, and the higher the evaluation after tasting, the more likely people choose enterprise brand fruits. In addition, consumers who have not tasted or whose relatives and friends have not bought enterprise brand fruits are more likely to choose not to purchase enterprise brand fruits.

4.2. Countermeasures and Suggestions. Given the above influencing factors, To promote consumers' purchasing enterprise brand fruits, the following countermeasures and suggestions are put forward.

Firstly, expand the marketing channels of enterprise brand fruits and improve the convenience of purchase. The survey finds that consumers purchasing fruits in supermarkets and fruit stores account for the higher proportion: they are $68.91 \%$ and $55.77 \%$, respectively. Therefore, more enterprise brand fruits should be put in supermarkets and fruit stores. In addition, with the rise of the network 
economy, the convenience of online shopping is highlighted. $36.54 \%$ of consumers purchase fruits in online stores. So giving full play to the role of the internet, establishing online stores through e-commerce platforms is one of the important ways to sell enterprise brand fruits in the future.

Secondly, improve the quality of enterprise brand fruits and pay attention to the improvement of taste. The survey respondents generally believe that there is a difference between enterprise brand fruits and common fruits (39.74\%). The biggest difference lies in quality and safety (69.87\%), and referring to the most important factor when choosing the way to purchase enterprise brand fruits, the quality assurance accounts for $61.22 \%$. Therefore, improving the level of enterprise brand fruits quality certification is an important way. At the same time, improving the taste of enterprise brand fruits should be paid more attention to. The survey finds that $42.95 \%$ of respondents think the taste has a great influence on purchasing enterprise brand fruits. This also shows that, with the continuous improvement of people's income level, "high quality and high price" has gradually been recognized by consumers, and they have put forward higher requirements for consumption experience.

Thirdly, give full play to the publicity role of the government and enterprises, and improve the popularity of enterprise brand fruits. The respondents generally believe that the government and enterprises publicity is low (88.14\%), while taste and evaluation after tasting play important roles in purchasing enterprise brand fruits. So enterprises should regularly carry out the publicity, put forward activities such as foretaste, let more consumers have first-hand experience to enterprise brand fruits, improve their reputation, use the leading role among customers, improve the consumers utility, and at the same time increase the sales of enterprise brand fruits.

In the future, the study will focus on the quality, safety, channels, services, property rights, and other aspects of brand fruits and vegetables and will discuss the relationship of the various elements' dimensions. The study will also discover the most important aspects that influence consumers' purchase behavior. The limitations of the study mainly lie in the selection of samples and sample size since different groups have different degrees of cognition and will give different answers. The sample size also has an impact on the results of the study.

\section{Data Availability}

On the basis of the theoretical framework, the questionnaire is designed, which is divided into three parts: cognition and attitude of corporate brand fruit, basic personal and family information, and purchasing behavior and characteristics of corporate brand fruit. The definition of indicators in the questionnaire is shown in Table 1. In March 2021, the questionnaire was revised on the basis of the presurvey, and the final questionnaire is issued through the Questionnaire Star platform. 312 questionnaires were collected; the effective rate is $100 \%$. The data that support the findings of this study are available from the corresponding author upon reasonable request.

\section{Conflicts of Interest}

The authors declare that there are no conflicts of interest regarding the publication of this article.

\section{Authors' Contributions}

All the authors of the study agreed to sign and have reached a consensus on the order of signature before submission. All the authors of the study read the article and agreed to contribute to the publication.

\section{Acknowledgments}

This study was funded by the project: Strategic Planning on Rural Revitalization of Jimo District (2018-2022) (660/ 2418726).

\section{References}

[1] R.-F. Liu, T. Chen, L. Leng, and D. Feng, "Empirical analysis on the consumer purchase behavior on geographical indications agricultural products--base on the surveys of consumers from Shanghai, Beijing and Zhengzhou," System Sciences and Comprehensive Studies in Agriculture, vol. 27, no. 4, pp. 453-462, 2011.

[2] H.-C. Liu, "The empirical analysis of apple consumption behavior in China," China Fruit News, vol. 19, no. 5, pp. 10-12, 2003.

[3] J.-H. Liu, Study on Influencing Factors of Consumer Lifestyle on Purchasing Behavior of Fresh Fruit, University of International Business and Economics, Beijing, China, 2014.

[4] R. Huang and Q.-E. Jiang, "Analysis on the influencing factors of fruit consumption in China," Fujian Agricultural Science and Technology, vol. 11, pp. 57-64, 2020.

[5] J.-Y. Yang, B.-L. Tang, and Y. Jiang, "Research on purchase intention of consumer for buying fresh agricultural products in small and medium sized city," Statistics \& Decisions, vol. 12, pp. 115-117, 2013.

[6] L.-Y. Chen, The Survey of Consumer Behavior Both Buying Apples and Preference of Apple Characteristic in Shaanxi Province, University of Ningxia, Yinchuan, China, 2015.

[7] H. Sun, Consumer Purchase Behavior to Pay for Fresh Vegetable of Supermarket in Changchun, University of Yanbian, Yanji, China, 2015.

[8] Y.-K. Yao, H. Yu, and H.-W. Sun, "Investigation and analysis on consumption characteristics and demand preference in Jiangsu grape market," Jiangsu Agricultural Science and Technology, vol. 11, pp. 57-64, 2020.

[9] L. Zhang, N. Wang, and S. Zhao, "Research on consumption behavior and retail terminal layout of fresh agricultural products in small and medium city-taking vegetable retail terminal in Yantai of Shandong province as an example," Issues in Agricultural Economy, vol. 34, no. 6, pp. 74-81, 2013.

[10] J. Wang, A Study on Channel Choice of Fresh Fruit Purchase Influencing Factors for Young People in Shushan District of Hefei, South-Central University for Nationalities, Wuhan, China, 2019.

[11] M. Maruyaman and L. V. Trung, "Traditional bazaar or supermarket: a profit analysis of affluent consumer perceptions in Hanoi," International Review of Retail Distribution \& Consumer Research, vol. 17, no. 3, pp. 233-252, 2007. 
[12] Z.-Y. Yin, C.-X. Tian, and Z. Zhu, "Analysis of consumer behavior for purchasing fresh agricultural products online in developed areas - based on survey data of 5730 questionnaires in Suzhou," Economic and Trade Update, vol. 26, pp. 24-28, 2016.

[13] Y.-Q. Yang, "Research on customer's purchase behavior of fruit products based on WeChat moments," Value Engineering, vol. 37, no. 18, pp. 49-51, 2018.

[14] C.-Y. Li, Initial Comment and Additional Comment Information on Fresh Fruit Sales Impact Study, Heilongjiang Bayi Agricultural University, Daqing, China, 2020.

[15] S. Bolek, "Food purchasing, preservation, and eating behavior during COVID-19 pandemic: a consumer analysis," Italian Journal of Food Science, vol. 33, no. 3, pp. 14-24, 2021.

[16] S. Aday and M. S. Aday, "Impact of COVID-19 on the food supply chain," Food Quality and Safety, vol. 4, no. 4, pp. 167-180, 2020.

[17] K. Nirmal Ravi Kumar and S. Chandra Babu, "Value chain management under COVID-19: responses and lessons from grape production in India," Journal of Social and Economic Development, vol. 23, no. 3, pp. S468-S490, 2021.

[18] G.-D. Huang, L.-Z. Lu, and W.-L. Huang, "Investigation on pesticide residues in fruits and vegetables in Guangdong province-investigation on consumers' awareness and purchase behavior of pesticide residues in fruits and vegetables," Journal of Anhui Agricultural Sciences, vol. 46, no. No.14, pp. 185-187, 2018.

[19] S.-H. Gao, L.-Y. Cao, and L.-M. Xie, "Research on consumer's cognition and purchase behavior for pesticide residue of fruits and vegetables-survey based on consumers' in Shaanxi province," Shaanxi Journal of Agricultural Sciences, vol. 60, no. 3, pp. 103-106, 2014.

[20] S. Bolek, "Consumer knowledge, attitudes, and judgments about food safety: a consumer analysis," Trends in Food Science \& Technology, vol. 102, pp. 242-248, 2020.

[21] B.-L. Tang and X.-H. Li, "Authentication trust impact on consumer behavior of fruits and vegetables," Jiangsu Agricultural Sciences, vol. 47, no. 3, pp. 343-346, 2019.

[22] B. Zhang and J.-B. Lin, "Research on influence factors of consumer purchase behavior for traceability fruit-based on a comprehensive perspective of psychological reactions," Consumer Economics, vol. 30, no. 1, pp. 51-57, 2014.

[23] L.-J. Wu and Z. Wang, "Analysis on awareness and purchase behavior of brand vegetables -- Based on research data in Hebei province," Vegetable, vol. 10, pp. 1-4, 2013.

[24] R.-Y. Huang and Y. Tang, "Study on influencing factors of consumers' purchasing behavior for agricultural regional brand - taking fruit types of regional brands in Sichuan province as an example," Modern Marketing, vol. 5, pp. 74-78, 2020.

[25] Investigation and Thinking for Purchase Behavior of Grape and Pear in Zhejiang Province, Zhejiang Statistics, vol. 9, , pp. 29-30, 2002.

[26] Z.-Y. Xiang and Q.-L. Li, "Research on the influence of brand authenticity of agricultural products on brand evangelism," Journal of Huazhong Agricultural University (Social Sciences Edition), vol. 3, pp. 91-99, 2020.

[27] D. Tang and Z. Wen, "Test for bias in common methods: problems and recommendations," Psychological Science, vol. 43, no. 1, pp. 215-223, 2020.

[28] H. Zhou and L. Long, "Statistical Test and control method of common method deviation," Advances in Psychological Science, vol. 12, no. 6, pp. 942-950, 2004. 